\title{
The Evaluation of CFIP Lumina in RoF Networks
}

\author{
A. Bogdanovs \\ SAF Tehnika, \\ Ganibu dambis str., LV-1010 Riga, Latvia, phone: +37129138319,e-mail:andrejs.bogdanovs@saftehnika.com
}

J. Porins

Institute of Telecommunications, Riga Technical University,

Azenes str.12, LV-1010 Riga, Latvia, phone: +37127896222,e-mail: jurgis.porins@rtu.lv

\section{Introduction}

The need for higher capacity in backbone and in last mile networks increases each day, as the number of users grows. Therefore need for expanding and improving existing and also building new networks is a must for ISP (Internet service providers) to satisfy client needs. To provide integrated broadband services, these systems will need to offer data transmission capacities well beyond the present-day standards of wireless systems [3]. At the moment the highest capacity for network can be achieved using optical networks. But unfortunately there are situations when optical fiber cannot be used and therefore in these cases a different technology mesh must be used. As a promising and affordable solution is to use the RoF (Radio over Fiber) systems [1-5]. It is possible to say that a ROF system consists of two parts: optical part and radio part or ROF is the combined product of optical and radio engineering. Optical networking technologies are leveraged to reach the longer transmission distance over a single-mode fiber (SMF) and to integrate with the WDMPON between the base station and central office [3].

One of the RoF products, called "CFIP Lumina", is manufactured by join-stock Company "SAF Tehnika" located in Riga, Latvia,

\section{System setup}

CFIP Lumina is full microwave radio outdoor solution supporting electrical and also optical interface. CFIP Lumina supports $7 / 8 ; 10 / 11 ; 13 / 15 ; 18 / 23$; 24(unlicensed); 26; $38 \mathrm{GHz}$ ETSI frequency bands and 11; 18; 23; 24(unlicensed); $38 \mathrm{GHz}$ FCC frequency bands with 14, 28, 40 and $56 \mathrm{MHz}$ bandwidth according to ETSI standard, and 20,30, 40, $50 \mathrm{MHz}$ according to FCC standard. CFIP Lumina radio frequency stability is within $+/-7$ ppm. The traffic interface is Ethernet - electrical or optical with maximum jumbo frame size of 9728 bytes.
CFIP Lumina uses modulations from QPSK to 256QAM and capacity from $17-366 \mathrm{Mbps}$ full duplex bidirectional traffic in $1+0$ applications.

Maximum radio transmitting power for CFIP Lumina varies from $-2 \mathrm{dBm}$ to $+27 \mathrm{dBm}$ depending on used frequency band and modulation. For example Tx power for 256QAM modulation is $+20 \mathrm{dBm}$ using $7 / 8 \mathrm{GHz} ;+17$ $\mathrm{dBm}$ using 10,11,13,15 GHz, $+12 \mathrm{dBm}$ using 18,23,26 Ghz, $-2 \mathrm{dBm}$ using $24 \mathrm{GHz}$ and $+10 \mathrm{dBm}$ using $38 \mathrm{GHz}$ frequency bands.

The minimum RSL (received signal level) values for CFIP Lumina radios for 256 QAM modulation are -69 $\mathrm{dBm}$ using $14 \mathrm{MHz}$ bandwidth with bitrate of $88 \mathrm{Mbps}$, $66 \mathrm{dBm}$ using $28 \mathrm{Mhz}$ bandwidth with bitrate of 176 Mbps, $-65 \mathrm{dBm}$ using $40 \mathrm{MHz}$ bandwidth with bitrate 248Mbps and $-62 \mathrm{dBm}$ using $56 \mathrm{MHz}$ bandwidth with bitrate 363 Mbps [7].

CFIP Lumina main features are:

- Interfaces: 1-2 ports (optical or electrical) 10/100/1000 BaseT Ethernet;

- Ethernet traffic supports QoS with 4 priority queues, essential for ACM use;

- VLAN configuration for user and management traffics;

- Software limited link capacity by licence key;

- Power consumption: $25-35 \mathrm{~W}$;

- GUI (Graphical User Interface) management.

One of the main features for CFIP Lumina is ACM (Adaptive Coding Modulation) which is hitless and improves link utilization, maintaining the highest link spectral efficiency possible at any given time in any link condition. The basics of ACM are shown on Fig. 1.

CFIP Lumina supports also QOS (Quality of Service) which can be configured in 4 priority queues whether using DIffServ (DSCP) or 802.1p mapping. CFIP Lumina supports also port-based priorities and 802.1p bandwidth limiting for each port and priority. Explanation for QOS operation is given in Fig. 2. 


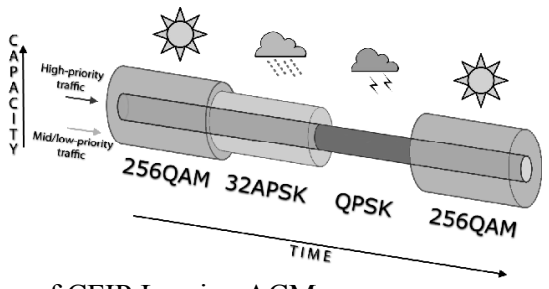

Fig. 1.Basics of CFIP Lumina ACM

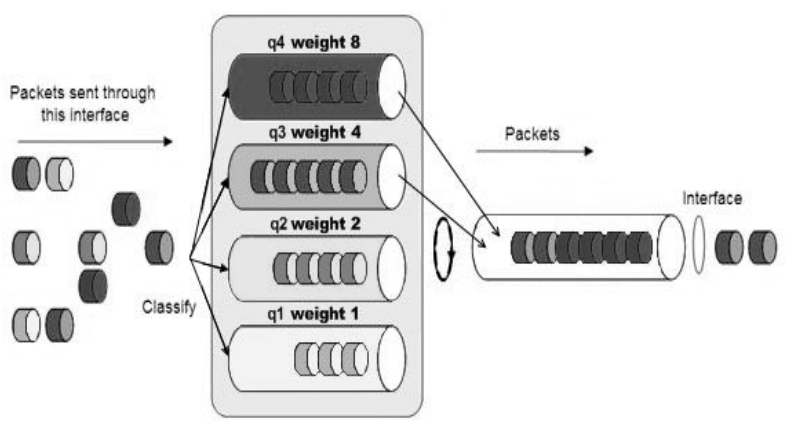

Fig. 2. Basics of CFIP Lumina QOS

Often in networks VLAN (Virtual Local Area Network) tagging is used to gain better traffic stability, performance and data protection. CFIP Lumina supports up to 4093 VLAN IDs with separation of management and user traffic, it also supports 3 VLAN types: Trunk, Access and Management. To understand better the benefit of using VLAN tagging an example is given in Fig. 3.

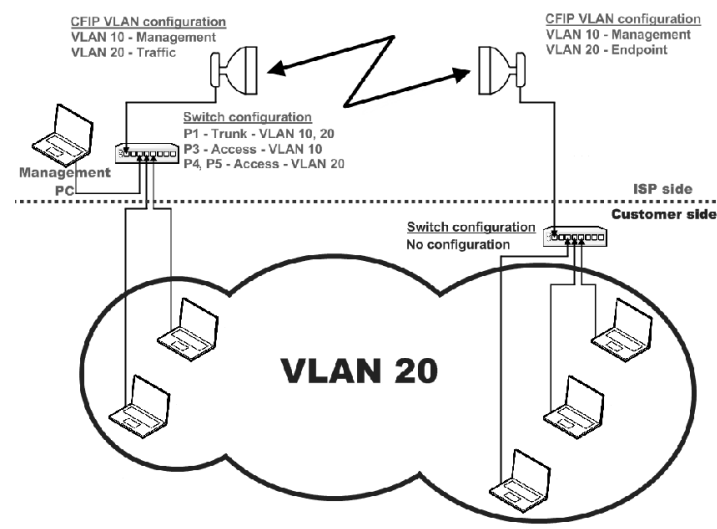

Fig. 3. Example of CFIP Lumina Vlan configuration

\section{Description of the Experiments}

CFIP Lumina optical interface is accessible through ODC plug located on FODU, client can choose whether use one or two ODC connectors. ODC connectors are fully hermetic. CFIP Lumina can support multimode fiber with wavelength $850 \mathrm{~nm}$, single mode fiber with wavelength $1310 \mathrm{~nm}$ and $1550 \mathrm{~nm}$. For example CFIP Lumina optical parameters for $1310 \mathrm{~nm}$ single mode fiber are:

- Optical output power: $-9 \mathrm{dBm}$;

- Guaranteed fiber length without amplification between 2 CFIP Lumina FODU: $10 \mathrm{~km}$;

- Working temperature: $-40{ }^{\circ} \mathrm{C}$ to $+80{ }^{\circ} \mathrm{C}$.

Transmitter section consists of a $1310 \mathrm{~nm}$ INGaAsP laser in an eye safe optical subassembly (OSA) which mates to the fiber cable.

The receiver utilizes InGaAs PIN photodiode mounted together with a trans-impedance preamplifier.
The CFIP Lumina complies with 21CFR 1040.10 and 1040.11 therefore it is labeled as Class 1 Laser Product. CFIP Lumina transmitter spectrum with $3 \mathrm{~dB}$ attenuation is shown on Fig. 4.

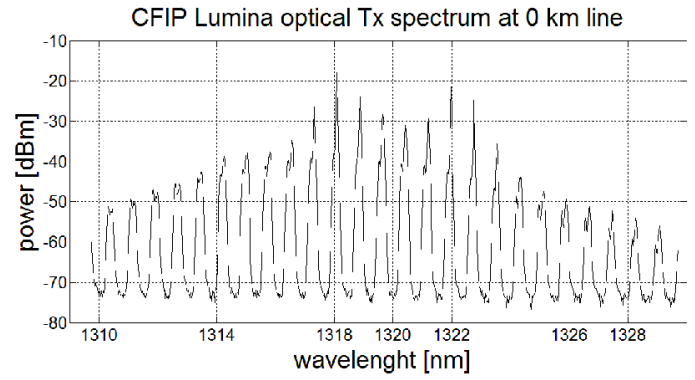

Fig. 4. CFIP Lumina received spectrum at $0 \mathrm{~km}$ line with $3 \mathrm{~dB}$ attenuation

From spectrum it is seen that transmitter spectrum is quite wide: from $1310 \mathrm{~nm}$ till $1320 \mathrm{~nm}$ with central mode at $1318 \mathrm{~nm}$. In laboratory experiment where the aim was to measure transmitter emitted central wavelength stability, gained results changing attenuation for transmitter and measured wavelength stability results can be found in table 1, and measurement schematics in Fig. 5

Table 1. Wavelength stability measurements

\begin{tabular}{|c|c|}
\hline Attenuation $(\mathrm{dB})$ & Central wavelength $(\mathrm{nm})$ \\
\hline 0 & 1318,3 \\
\hline 5 & 1320,8 \\
\hline 10 & 1320,8 \\
\hline 15 & 1320,8 \\
\hline 20 & 1320,8 \\
\hline 25 & 1320,8 \\
\hline 30 & 1320,8 \\
\hline
\end{tabular}

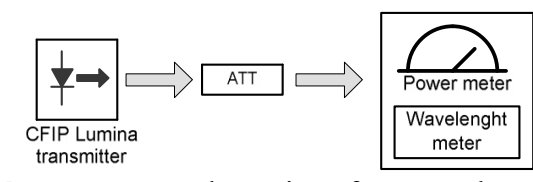

Fig. 5. Measurement schematics for wavelength stability measurements

Experiment was repeated with another side of radio to ensure wavelength stability and estimate difference between two CFIP Lumina transmitters. Measured results can be found in table 2 .

Table 2. Wavelength stability measurements

\begin{tabular}{|c|c|}
\hline Attenuation $(\mathrm{dB})$ & Central wavelength (nm) \\
\hline 0 & 1321,7 \\
\hline 5 & 1322,5 \\
\hline 10 & 1322,5 \\
\hline 15 & 1322,5 \\
\hline 20 & 1322,5 \\
\hline 25 & 1322,5 \\
\hline 30 & 1322,5 \\
\hline
\end{tabular}

The difference between 2 transmitters does not exceed $4,5 \mathrm{~nm}$ and that is normal, because it is clear that these transmitters is non etalon and may wary from each other. 
Further experiments were made according to schematic in Fig. 6 to ensure and measure CFIP Lumina optical transmitter reliability and operationally using 0,20 , 40, 60, $80 \mathrm{~km}$ long fiber.

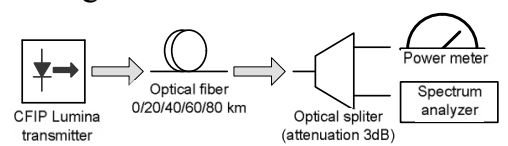

Fig. 6. Measurement schematics for spectrum and optical power measurements

Optical signal spectrum at $0 \mathrm{~km}$ line length and optical power in this case was $-9,82 \mathrm{dBm}$ (Fig.4). After $20 \mathrm{~km}$ line optical transmitter spectrum is shown in Fig. 7 and optical power was $-16,79 \mathrm{dBm}$.

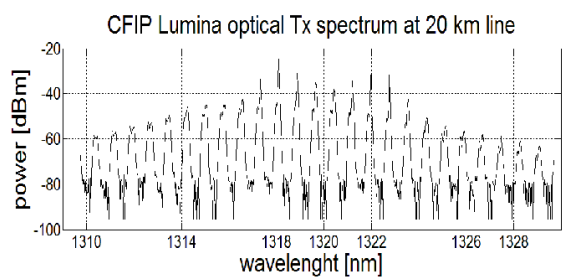

Fig. 7. CFIP Lumina received spectrum at $20 \mathrm{~km}$ line with $3 \mathrm{~dB}$ attenuation

Situation after $40 \mathrm{~km}$ line is shown in Fig. 8 and optical transmitter power was $-23,95 \mathrm{dBm}$.

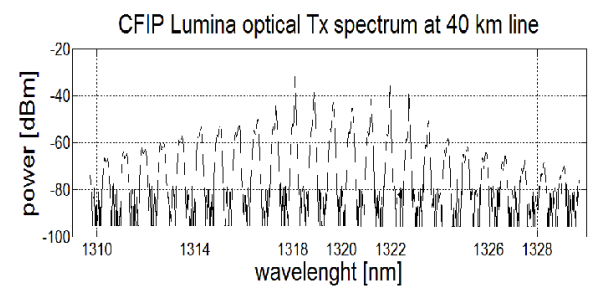

Fig. 8. CFIP Lumina received spectrum at $40 \mathrm{~km}$ line with $3 \mathrm{~dB}$ attenuation

Situation after $60 \mathrm{~km}$ line is shown in Fig. 9 and measured optical transmitter power was $-31,14 \mathrm{dBm}$.

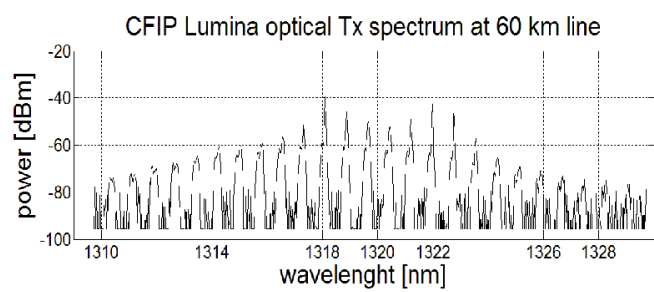

Fig. 9. CFIP Lumina received spectrum at $60 \mathrm{~km}$ line with $3 \mathrm{~dB}$ attenuation

Situation after $80 \mathrm{~km}$ line is shown in Fig. 10 and transmitter optical power was $-38,54 \mathrm{dBm}$.

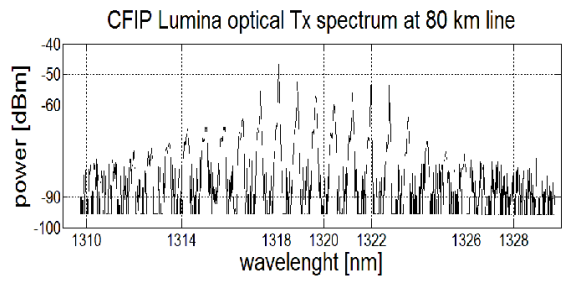

Fig. 10. CFIP Lumina received spectrum at $80 \mathrm{~km}$ line with $3 \mathrm{~dB}$ attenuation
Next experiment was made to measure CFIP Lumina optical receiver threshold (Fig.11). As a transmitter or emitting light source one of the CFIP Lumina transmitters was used. Measured signal threshold was $-19 \mathrm{dBm}$ what means that optical fiber length can be $20 \mathrm{~km}$ using CFIP Lumina transmitter (regarding to previous experiment) unlike datasheet where $10 \mathrm{~km}$ is written.

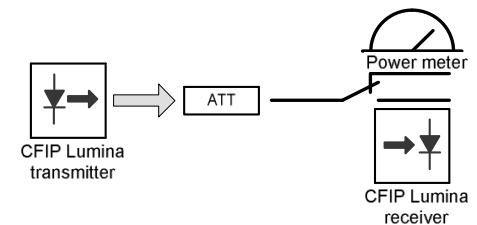

Fig. 11. Measurement schematics for optical receiver signal threshold measurements

To discuss benefits of this product another aspect is to estimate Ethernet capacity. To measure Ethernet capacity an Agilent N2x tester was used. The schematics and measurements were made according to RFC 2544 standard. This standard was established by the Internet Engineering Task Force (IETF) to outline the tests required and prove performance criteria for carrier Ethernet networks. In case when our interested product has to be used together with fiber optics, we are interested in highest capacity of it, therefore measurements were made only for bandwidth of $56 \mathrm{MHz}$ and modulation 256QAM using weak FEC. The results are shown in table Nr. 3

Table 3. CFIP Lumina throughput and latency measurement results

\begin{tabular}{|c|c|c|c|c|c|}
\hline $\begin{array}{c}\text { Frame } \\
\text { size }\end{array}$ & $\begin{array}{c}\text { Frame } \\
\text { Rate (F/s) }\end{array}$ & $\begin{array}{c}\text { Throughput } \\
\text { (Mbps) }\end{array}$ & \multicolumn{3}{|c|}{ Latency (us) } \\
\hline \multicolumn{6}{|c|}{ CFIP LUMINA 256QAM 56MHZ BANDWIDTH } \\
\hline $\mathbf{6 4}$ & 635463.000 & 325.36 & 91.860 & 93.010 & 341.470 \\
\hline $\mathbf{1 2 8}$ & 335990.300 & 344.05 & 94.760 & 95.852 & 291.570 \\
\hline $\mathbf{2 5 6}$ & 172809.133 & 353.91 & 100.560 & 101.624 & 275.200 \\
\hline $\mathbf{5 1 2}$ & 87670.367 & 359.10 & 112.070 & 113.233 & 253.600 \\
\hline $\mathbf{1 0 2 4}$ & 44207.200 & 362.15 & 135.090 & 136.514 & 277.450 \\
\hline $\mathbf{1 2 8 0}$ & 35426.700 & 362.77 & 146.760 & 148.199 & 286.300 \\
\hline $\mathbf{1 5 1 8}$ & 29893.767 & 363.03 & 157.610 & 159.047 & 317.990 \\
\hline $\mathbf{9 1 9 2}$ & 4937.967 & 363.12 & 509.480 & 510.523 & 513.820 \\
\hline
\end{tabular}

When all important transmitting parameters of this product are known, it can be analyzed from its utilization point of view. It is obvious that this product covers most part of radio transmitting frequency bands including also unlicensed $24 \mathrm{GHz}$ bandwidth and from the radio part this product definitely is very interesting for most of telecommunication operators and ISP. Also this product is reliable and has FEC which increases radio receiver thresholds in each modulation and bandwidth. The use of ACM will guaranty, that CFIP Lumina link will never stop to work, it will simply switch lover modulation in bad weather conditions, of course the client for that moment will lose capacity of link, but using the QOS will guaranty that highest priority traffic, for example such as voice, voip or video will not be lost. It is understandable, that maximum radio bitrate of 363 Mbps using 1518 bytes frame size in $1+0$ link state is quite good parameter and together with low latency it is possible to surly say that the interest of this product will only rise. The radio transmitter 
power range is also enough to provide distance for last mile solutions and also as a part for backbone network.

\section{Conclusions}

Optical Ethernet connections of CFIP Lumina provide excellent protection against lightning strikes and allow a long distance between user equipment and CFIP Lumina FODU what is the most benefit of ROF systems. The support of 3 optical windows is also a gain for clients.

As optical part measurements showed that in case when low optical attenuation was used it was possible to observe central wavelength fluctuation, which decreased as optical attenuation rise. Interesting thing was that wavelength meter showed central wavelength at $1322 \mathrm{~nm}$, but regarding to spectrum it was $1318 \mathrm{~nm}$. Apparently in this case if the transmitter will not change during the time, CFIP Lumina cannot be used in WDM - PON systems. But if costumer needs to use it then appropriate and different transmitting SFP module can be used.

Separate cables for DC to power the unit and fiber optics to provide traffic allow flexibility to run these cables from different locations if needed. Also 2 separate optical Gigabit ports on FODU provide advanced configuration opportunities if client is needed in that.

With all these features CFIP Lumina is very flexible product for telecommunication market. It can improve and fit in existing telecommunication networks or be a part or even one of the main components in creating new modern on optical fiber based networks.

\section{References}

1. Alphones A. Double-spread radio-over-fiber system for next-generation wireless Technologies// Journal of Optical Networking, 2009. - No. 2(8). - P. 225-234.

2. Shams H., Kaszubowska-Anandarajah A., Perry P., Barry L. Demonstration and optimization of an optical impulse radio ultrawideband distribution system using a gainswitched laser transmitter // Journal of Optical Networking, 2009. - No. 2(8). - P. 179-187.

3. Yu J., Chang G., Koonen A., Ellinas G. Radio-overoptical-fiber networks: introduction to the feature issue // Journal of Optical Networking, 2009. - No. 5(8). - P. 488490.

4. Vegas O. J. J. , Kuri T., Kitayama K. Half-duplex 12 channel dense WDM 2.6-GHz-band radio-over-fiber system employing a $1.5 \mathrm{GHz}$ bandwidth reflective semiconductor optical amplifier // Journal of Optical Networking, 2008. - No. 12(7). - P. 989-994.

5. Dong Z., Lu J., Cao Z., Chen L. Low-cost optical line terminal for a WDM-PON compatible with radio-over-fiber system Journal of Optical Networking, 2009. - No. 3(8). - P. 244-248.

6. Le Derickson D., Muller M. Digital Communications Test and Measurement. Boston, Personal Education - 2008. - 953 p.

7. Navickas Z., Žvironienė A., Rindzevičius R., Tervydis $\mathbf{P}$. Performance Analysis of telecommunication System with Feedback Control Mechanism // Electronics and Electrical Engineering. - Kaunas: Technologija, 2010. - No. 9(105). - P. 3-8.

\footnotetext{
A. Bogdanovs, J. Porins. The Evaluation of CFIP Lumina in RoF Networks // Electronics and Electrical Engineering. - Kaunas: Technologija, 2011. - No. 2(108). - P. 23-26.

ROF systems become a significant part of modern telecommunication industry, therefore separate product estimation become more required. CFIP Lumina produced by join-stock Company "SAF Tehnika" is one of the new products in this telecommunication field and needs to be analyzed regarding to potential customer needs. CFIP Lumina is flexible product with a lot of potential and lot of features and definitely is one of interesting product in self kind. Ill. 11, bibl. 6, tabl. 3 (in English; abstracts in English and Lithuanian).
}

\footnotetext{
A. Bogdanovs, J. Porins. CFIP „Lumina” evoliucija RoF tinkluose // Elektronika ir elektrotechnika. - Kaunas: Technologija, 2011. - Nr. 2(108). - P. 23-26.

Šiuolaikinèje telekomunikacinèje pramonèje daug dèmesio skiriama ROF sistemoms. Todèl būtina ịvertinti atskirus posistemius. CFIP „Lumina“ gaminama uždarojoje akcinèje bendroveje „SAF Tehnika“. Šioje rinkoje tai vienas naujausių gaminių, kurio analizę reikia atlikti. Nustatyta, kad CFIP „Lumina“ yra daugiafunkcis produktas. Il. 11, bibl. 6, lent. 3 (anglų kalba; santraukos anglų ir lietuvių k.).
} 